\title{
PENGARUH KONSENTRASI NACL TERHADAP PARAMETER ELASTIK PASIR TERSATURASI
}

\author{
MUAMMAR QADAFI' ${ }^{1}$, USMAN MALIK ${ }^{2}$
}

1. Program Studi Teknik Lingkungan, Institut Teknologi Bandung, Bandung

2. Jurusan Fisika, Universitas Riau, Pekanbaru

Email : gadafim.mq@gmail.com

\begin{abstract}
ABSTRAK
Telah dilakukan penelitian mengenai pengaruh konsentrasi larutan natrium klorida ( $\mathrm{NaCl}$ ) yang disaturasikan pada sampel (core) pasir terhadap parameter elastik. Core dibuat dengan diameter $7,5 \mathrm{~cm}$ dan panjang $10 \mathrm{~cm}$. Core dicetak dengan tekanan sebesar $5,8 \times 10^{4} \mathrm{~N} / \mathrm{m}^{2}$. Core yang telah dicetak disaturasi dengan larutan $\mathrm{NaCl}$ yang divariasikan kosentrasinya dari 0 ppm hingga 360000 ppm (titik jenuh $\mathrm{NaCl}$ ) selanjutnya dirambatkan gelombang seismik/elastik menggunakan Sonic Wave Analyzer (SOWAN), dari pengukuran ini akan diperoleh waktu tempuh gelombang (delay) pada sampel. Berdasarkan waktu tempuh, kecepatan gelombang primer dan sekunder pada Core diketahui. Hasil yang diperoleh berupa parameter elastisik dari Core seperti modulus Young, Modulus Bulk, Modulus Geser dan Konstanta Lame. Modulus Young Core berkisar antara $7,8 \times 10^{7} \mathrm{~Pa}-1,8 \times 10^{9} \mathrm{~Pa}$, modulus Bulk sebesar $1,8 \times 10^{7} \mathrm{~Pa}-8,9 \times 10^{8} \mathrm{~Pa}$, modulus geser antara $5,1 \times 10^{7} \mathrm{~Pa}-7,6 \times 10^{8} \mathrm{~Pa}$ dan Konstanta Lame berkisar antara 1,8 $\times 10^{8} \mathrm{~Pa}-3,4 \times 10^{9} \mathrm{~Pa}$.
\end{abstract}

Kata kunci: Core Pasir Tersaturasi, Konsentrasi NaCl, Parameter Elastik.

\begin{abstract}
Research has been carried out on the effect of saturated sodium chloride ( $\mathrm{NaCl}$ ) solution concentration in sand samples (cores) on elastic parameters. This research was conducted to determine the differences in the elastic core parameters according to the concentration of $\mathrm{NaCl}$ that saturates them. The cores are made with a diameter of $7.5 \mathrm{~cm}$ and a length of $10 \mathrm{~cm}$. The cores are molded at a pressure of $5,8 \times 10^{4} \mathrm{~N} / \mathrm{m}^{2}$. The cores that have been printed are saturated with $\mathrm{NaCl}$ solution with varying concentrations from $0 \mathrm{ppm}$ to $360000 \mathrm{ppm}$ (saturation point of $\mathrm{NaCl}$ ) then propagated seismic/elastic waves using a Sonic Wave Analyzer (SOWAN), from this measurement the wave travel time (delay) will be obtained in the sample. Based on the travel time, the primary and secondary wave velocities at the Core are known. The core elastic parameters was obtained such as Young's modulus, Bulk modulus, Shear modulus and Lame's constant. Young Core modulus ranges from $7,8 \times 10^{7} \mathrm{~Pa}-1,8 \times 10^{9} \mathrm{~Pa}$, Bulk modulus of $1,8 \times 10^{7} \mathrm{~Pa}$ $8,9 \times 10^{8} \mathrm{~Pa}$, shear modulus between 5,1 $\times 10^{7} \mathrm{~Pa}-7,6 \times 10^{8} \mathrm{~Pa}$ and Lame Constant ranges between $1,8 \times 10^{8} \mathrm{~Pa}-3,4 \times 10^{9} \mathrm{~Pa}$.
\end{abstract}

Keywords: Saturated Sand Cores, NaCl Concentration, Elastic Parameters. 


\section{PENDAHULUAN}

$\mathrm{NaCl}$ merupakan komponen utama dari salinitas air laut. Salinitas air mempengaruhi elastisitas suatu material yang disaturasi (Xu et al., 2016), semakin besar densitas fluida yang menyaturasi suatu material maka kerapatan material semakin besar, sedangkan semakin kecil saturasi fluida maka kepadatan partikel material tersebut akan semakin kecil pula dan sifat ini bergantung pada jenis fluida yang menyaturasinya (Li et al., 2016). Jika tingkat kepadatan material semakin besar, maka semakin baik material tersebut merambatkan gelombang elastik. Medium yang memiliki susunan partikel yang lebih rapat merambatkan gelombang lebih baik.

Gelombang elastik telah digunakan dalam ilmu batuan sebagai media menentukan kekuatan batuan (Kang \& Lee, 2015). Parameter elastisitas batuan seperti modulus Young (E), modulus Bulk $(K)$, modulus geser/shear $(\mu)$ dan konstanta Lame $(\lambda)$ digunakan untuk menentukan kekuatan batuan terhadap tekanan (Ahied, 2010). Jika dilewatkan gelombang elastik pada batuan, maka diketahui kecepatan gelombang pada medium tersaturasi tersebut sehingga parameter elastic batuan dapat ditentukan (Ahied, 2010). Apabila diketahui cepat rambat gelombang pada suatu material berpori (core) yang disaturasi dengan nilai tertentu oleh air atau larutan (misalnya larutan $\mathrm{NaCl}$ ), maka dapat diketahui karakteristik material tersaturasi tersebut seperti elastisitas dan kekuatannya.

Kadar $\mathrm{NaCl}$ menentukan besarnya salinitas air laut disuatu perairan. Jika diketahui kadar $\mathrm{NaCl}$ yang menyaturasi pasir yang ada di pantai ataupun dasar laut, maka dapat diketahui parameter elastisitas pasir tersebut. Salinitas air juga berpengaruh pada resistivitas batuan yang dapat digunakan sebagai parameter menetukan karakteristik air yang terdapat pada lapisan akuifer (Qadafi et al., 2015). Mengetahui parameter elastisitas pasir yang tersaturasi air yang memiliki salinitas tinggi merupakan langkah awal untuk memulai pembangunan sarana di pantai tersebut seperti pembengunan jembatan, turap ataupun pelabuhan (Sudjianto, 2003).

Penggunaan metode perambatan gelombang elastik dalam menetukan parameter elastik batuan berpori seperti pasir merupakan metode lebih akurat dibandingkan metode destruktif (Kang \& Lee, 2015). Metode ini selain tidak merusak sampel juga dapat dilakukan untuk sampel batuan yang memiliki elastisitas yang kecil karena jika digunakan metode destruktif, nilai parameter elastiknya akan sulit untuk ditentukan karena keadaan pasir yang mudah hancur (Biot, 1998). Tegangan yang dihasilkan dari perambatan gelombang elastik dapat menghasilkan regangan sesaat sebelum partikel batuan kembali ke kondisi semula. Kemampuan partikel untuk kembali ke titik semula ini lah yang disebut dengan sifat elastik (Davis \& Selvadurai, 1996). Dengan mengetahui karakteristik gelombang elastik yang merambat pada media tersebut, maka sifat elastiknya akan dapat diketahui.

Penelitian ini bertujuan untuk mengetahuin pengaruh saturasi $\mathrm{NaCl}$ terhadap parameter elastik pasir seperti modulus Young, modulus Bulk, konstanta Lame dan modulus geser sebagai upaya mitigasi longsor dan kebutuhan pembangunan bangunan tepi pantai ditinjau dari salinitas air. 


\section{BAHAN DAN METODE}

\subsection{Alat dan Bahan}

Adapun peralatan yang digunakan dalam penelitian ini berikut fungsinya adalah sebagai berikut.

Tabel 2.1 Peralatan

\begin{tabular}{|c|c|c|}
\hline No & Nama Alat & Fungsi \\
\hline 1 & timbangan/neraca ohaus & \\
\hline 2 & gelas kimia & olume larutan dan menetukan \\
\hline 3 & pipa paralon 2,5 inch & n sampel \\
\hline 4 & compressior & $\begin{array}{l}\text { netukan tekanan sampel pada saat } \\
\text { n }\end{array}$ \\
\hline 5 & penje & jjepit sampel pada saat pengukuran \\
\hline 6 & $\begin{array}{l}\text { Sonic Wave Analyzer } \\
\text { (SOWAN) }\end{array}$ & $\begin{array}{l}\text { berfungsi sebagai generator pembangkit } \\
\text { gelombang seismik }\end{array}$ \\
\hline 7 & piezo transmitter & gelombang seismik \\
\hline 8 & piezo & $\begin{array}{l}\text { ai penerima } \\
\text { ai } \text { pengga }\end{array}$ \\
\hline 9 & komputer laptop & $\begin{array}{l}\text { monitor untuk menentukan waktu tempuh } \\
\text { gelombang }\end{array}$ \\
\hline 10 & kabel interface & penghubung antara SOWAN dan laptop \\
\hline
\end{tabular}

Bahan yang digunakan dalam penelitian ini adalah sebagai berikut:
a. Pasir (sebagai media/sampel)
b. $\mathrm{NaCl}$ (sebagai senyawa yang digunakan untuk menyaturasi sampel)
c. Air (untuk membuat larutan senyawa diatas)
d. Grease (untuk menyamakan impedansi transduser dan sampel)

\subsection{Pembuatan larutan $\mathrm{NaCl}$}

Larutan $\mathrm{NaCl}$ dibuat dengan konsentrasi 0 ppm-360000 ppm (1ppm=1mg zat/1 liter air). 360000 ppm $(6,15 \mathrm{M})$ merupakan titik jenuh larutan $\mathrm{NaCl}$ pada suhu kamar $\left(27^{\circ} \mathrm{C}\right)$. Volume air masing-masing $500 \mathrm{ml}$, massa $\mathrm{NaCl}$ divariasikan dari 0-180 gram. Massa $\mathrm{NaCl}$ ditimbang menggunakan neraca ohaus, sedangkan volume air diukur menggunakan gelas kimia.

\subsection{Pembuatan dan Analisis Core}

Core dibuat menggunakan cetakan berupa pipa paralon berdiameter $7,4 \mathrm{~cm}$. Saat pencetekan, core diberi tekanan menggunakan compression machine dengan tekanan sebesar $5,8 \times 10^{4} \mathrm{~N} / \mathrm{m}^{2}$ yang memberikan porositas sebesar $10,4 \%$. Tekanan yang digunakan tidak terlalu besar karena Core dianggap pasir permukaan. Parameter core seperti massa, massa jenis, volume ditentukan dengan pengukuran langsung. Perhitungan porisitas dilakukan dengan merendam Core dengan air. Core yang telah dicetak direndam dengan konsentrasi $\mathrm{NaCl}$ yang telah dipersiapkan sebelumnya selama lebih kurang 3 jam (pada jangka waktu ini larutan telah menyaturasi/mengisi seluruh pori-pori sampel). Core yang telah dipersiapkan dirambatkan gelombang elastik (seismik) dan waktu tempuh gelombang pada core diukur. Rangkaian eksperimen dapat dilihat pada Gambar 1. 


\subsection{Pengukuran Waktu Rambat Gelombang}

Core yang telah dipersiapkan dirambatkan gelombang elastik (seismik) dan waktu tempuh gelombang pada core diukur. Rangkaian eksperimen dapat dilihat pada Gambar 1.

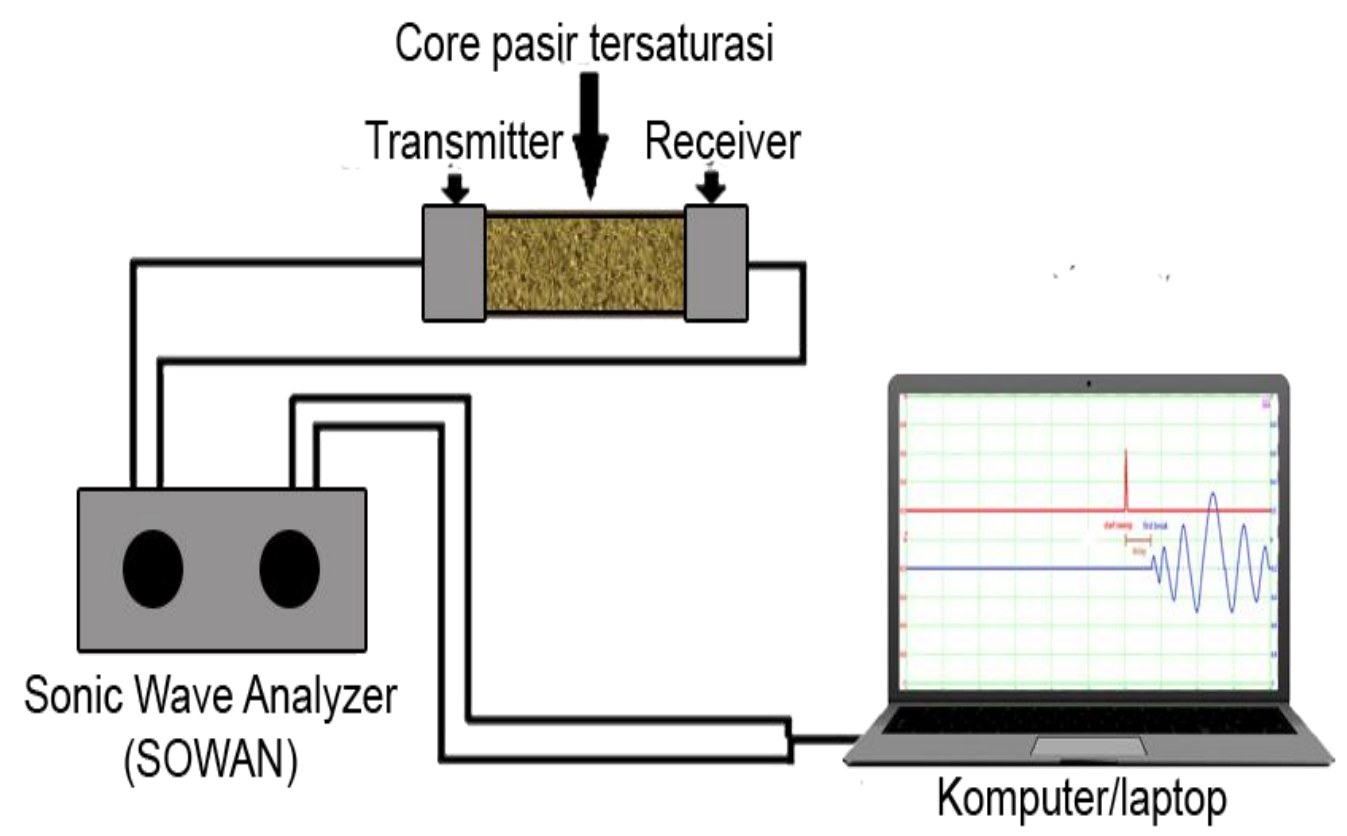

Gambar 1. Skema Pengukuran Waktu Tempuh Gelombang Elastik

Menggunakan prosedur susunan peralatan Gambar 1 didapatkan time delay (waktu perambatan gelombang ) pada sampel. Pengaukuran time delay dilakukan dalam dua tahap yaitu:

- Pengukuran Core Kering

Pengukuran dilakukan untuk menentukan parameter core yang belum disaturasi seperti modulus bulk, modulus young, modulus geser, dan poison rasio sampel asli (belum tersaturasi oleh fluida).

\section{- Pengukuran Core Tersaturasi}

Core yang telah tersaturasi diuji dengan merambatkan gelombang elastik, dan mengukur waktu rambat (time delay) gelombang primer dan sekunder pada core yang telah tersaturasi oleh larutan $\mathrm{NaCl}$ dengan konsentrasi yang di variasikan.

Time delay yang telah didapat dari pengaujian perambatan gelombang elastik pada masingmasing core diatas digunakan untuk menetukan kecepatan perambatan gelombang elastik, baik kecepatan gelombang primer (Vp) dan kecepatan gelombang sekunder (Vs), sehingga parameter-parameter elastisitas dari core dapat ditentukan. 


\subsection{Penentuan Parameter Elastik}

Parameter elastik ditentukan dengan mengetahuai kecepatan perambatan gelombang elastik, gelombang primer (Vp) dan gelombang sekunder (Vs), serta parameter core yang akan diukur. Paramter elastik core dapat ditentukan menggunakan persamaan berikut.

$$
\begin{aligned}
& v_{p}=\left(\frac{\lambda+2 \mu}{\rho}\right)^{1 / 2}=\left(\frac{k+\frac{4}{3} \mu}{\rho}\right)^{1 / 2} \\
& v_{S}=\sqrt{\frac{\mu}{\rho}} \\
& E=2\left(1+\frac{1-2\left(v_{S} / v_{P}\right)^{2}}{2-2\left(v_{S} / v_{P}\right)^{2}}\right) \mu
\end{aligned}
$$

\section{HASIL DAN PEMBAHASAN}

\subsection{Hubungan antara Konsentrasi $\mathrm{NaCl}$ dan Waktu Tempuh Gelombang Elastik}

Hubungan antara konsentrasi $\mathrm{NaCl}$ dan waktu tempuh (time delay) gelombang elastik primer dan sekunder pada core dapat dilihat pada Gambar 2. Terlihat jelas bahwa waktu tempuh berbanding terbalik dengan konsentrasi $\mathrm{NaCl}$. Hal ini karena semakin padat medium, maka waktu tempuhnya akan semakin kecil, kerapatan partikel mempermudah penjalaran vibrasi gelombang. Semakin kecil waktu tempuh berarti semakin baik sifat mekanik dari core, dan elastisitanya juga semakin besar.

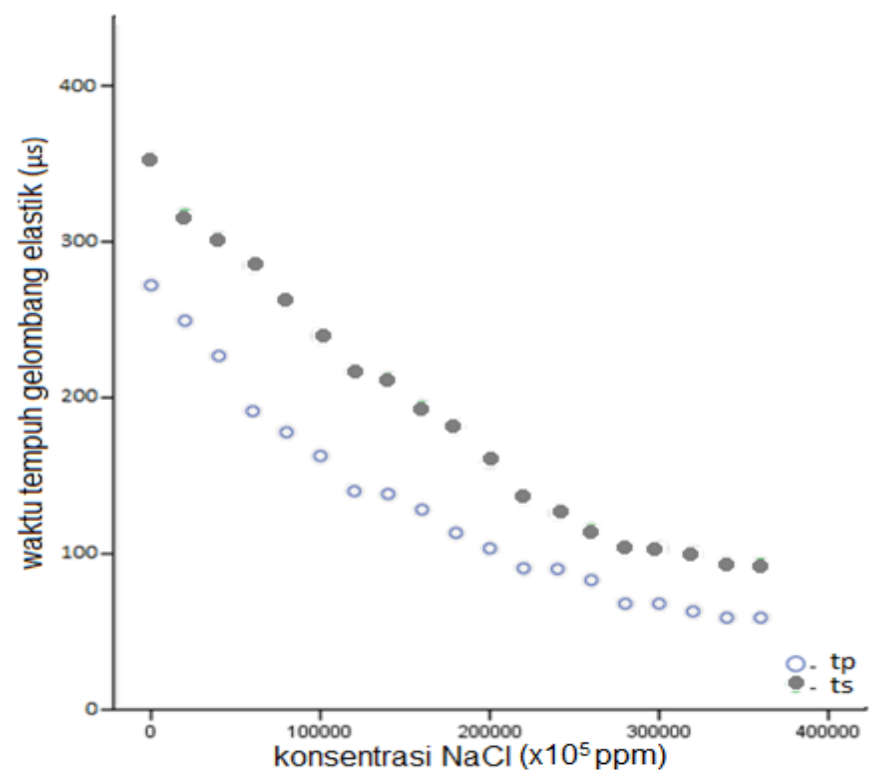

Gambar 2. Perubahan waktu tempuh terhadap perubahan konentrasi $\mathrm{NaCl}$ 


\subsection{Hubungan antara Konsentrasi $\mathrm{NaCl}$ dan Kecepatan Gelombang Elastik}

Hubungan antara Konsentrasi $\mathrm{NaCl}$ dan kecepatan gelombang elastik primer dan sekunder pada core dapat dilihat pada Gambar 3. Dapat dilihat bahwa kecepatan gelombang primer lebih besar dari kecepatan gelombang sekunder. Perubahan kecepatan gelombang primer dan sekunder berbanding lurus dengan perubahan konsentrasi $\mathrm{NaCl}$ yang disaturasikan pada core. Kecepatan gelombang primer pada sample core tersaturasi telah mendekati referensi kecepatan gelombang primer pada pasir tersaturasi air garam (air laut), yaitu sebesar 1,6$1,8 \mathrm{Km} / \mathrm{s}$ (Richardson, 1993). Hal ini dikarenakan semakin besarnya kerapatan partikel larutan yang mempermudah penghantaran vibrasi gelombang.

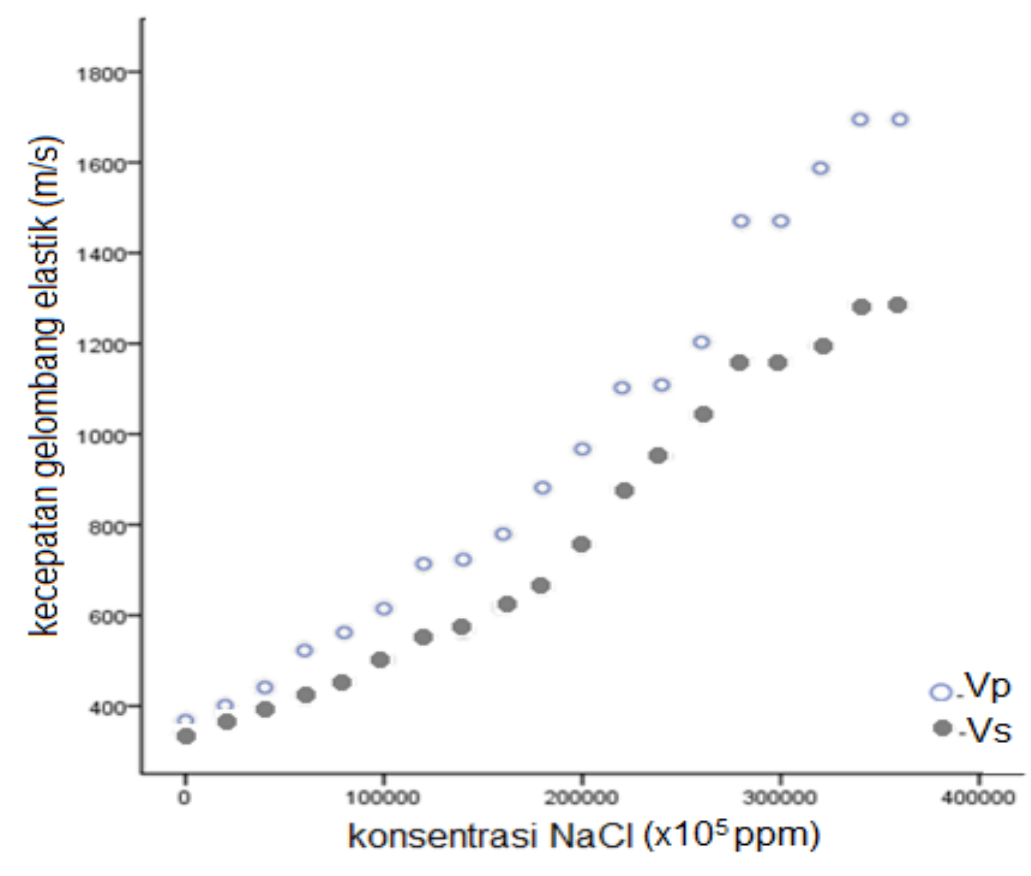

\section{Gambar 3. Hubungan kecepatan gelombang primer dan sekunder terhadap perubahan konsentrasi $\mathrm{NaCl}$}

\subsection{Hubungan antara Konsentrasi $\mathrm{NaCl}$ dan Parameter Elastik}

Hubungan antara konsentrasi $\mathrm{NaCl}$ terhadap modulus Young dari core dapat dilihat pada Gambar 4. Semakin besar konsentrasi NaCl, maka modulus elastisitas core semakin besar. Hal ini dikarenakan kerapatan partikel yang semakin besar akibat semakin besarnya konsentrasi $\mathrm{NaCl}$, sehingga nilai tekanan yang diperlukan untuk menimbulkan perubahan panjang core semakin besar. Berarti kemampuan core menahan gaya yang diberikan semakin besar (Zemansky, 1994).

Hubungan antara modulus Bulk core terhadap konsentrasi $\mathrm{NaCl}$ tidak jauh berbeda dengan modulus young (Gambar 4b). Kedua parameter elastisitas ini merupakan ukuran kemampuan core menahan perubahan tekanan dan mempertahankan keadaan dari core tersebut. Semakin besarnya konsentrasi $\mathrm{NaCl}$ menyebabkan semakin besarna gaya tarik-menarik antar partikel yang menyebabkan kemampuan core untuk mempertahankan volumenya saat dmerima tekanan semakin besar. Hal ini disebabkan karena larutan $\mathrm{NaCl}$ merupakan larutan elektrolit yang dapat memperkuat gaya tarik menarik tersebut (Sudjianto, 2003). Terlihat bahwa hubungan antara modulus Bulk dan konsentrasi $\mathrm{NaCl}$ pada titik-titik pengamatan 
mendekati bentuk kurva persamaan kuadrat. Ha ini dkarenakan hubungan antara kecepatan gelombanga elastik dan modulus Bulk merupakan hubungan kuadrat.
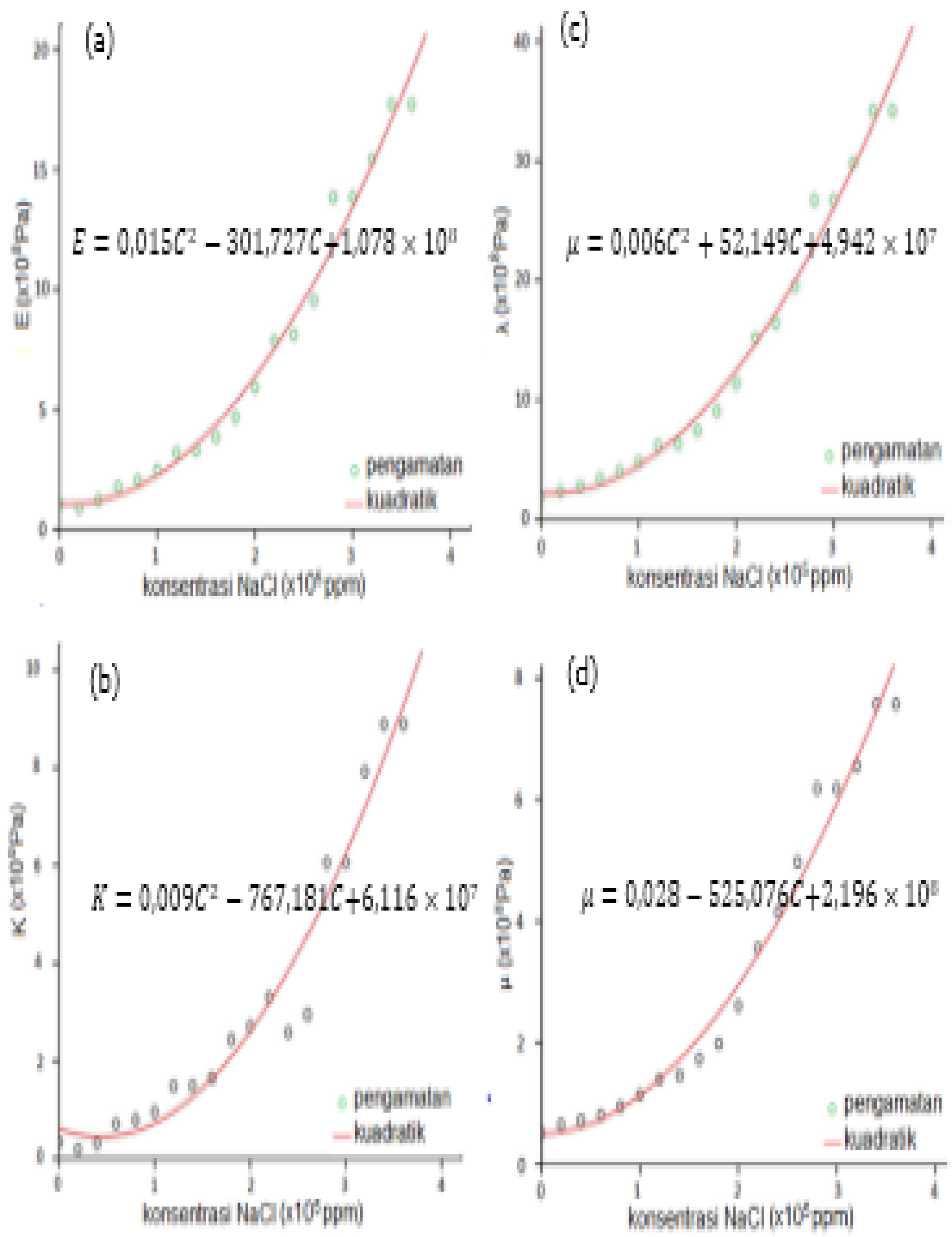

Gambar 4. Hubungan antara perubahan parameter elastisitas terhadap perubahan konsentrasi NaCl: (a) modulus Young, (b) modulus Bulk, (c) modulus Shear, dan (d) konstanta Lame.

Reka Lingkungan - 7 
Perubahan modulus geser terhadap perubahan konsentrasi $\mathrm{NaCl}$ juga tidak jauh berbeda dengan kedua parameter elastisitas sebelumnya (Gambar 4c). Modulus geser merupakan kemampuan suatu material untuk menahan perubahan bentuk saat menerima gaya geser. Semakin kuatnya gaya kohesi antara partikel sejenis yang ditimbulkan karena semakin besarnya konsentrasi $\mathrm{NaCl}$ yang menyaturasi core menyebabkan kemampuan core untuk mempertahankan keadaan saat menerima gaya geser semakin besar, dengan kata lain perbandingan antara tegangan geser dan regangan geser core semakin besar. Oleh sebab itu semakin besar konsentrasi, modulus Geser core akan semakin besar pula (Wang 1998; Sun et al., 2015).

Hubungan antara konsentrasi $\mathrm{NaCl}$ terhadap Konstanta Lame dari sampel core dapat dilihat pada Gambar 4d. Nilai Konstanta Lame juga sebanding dengan konsentrasi NaCl. Semakin besar konsentrasi $\mathrm{NaCl}$ maka konstanta Lame juga akan semakin besar. Konstanta Lame memiliki kesamaan dengan modulus Bulk. Konstanta Lame juga merupakan kemampuan suatu material untuk mempertahankan keadaan saat material tersebut menerima tekanan dari luar (Sun et al., 2015).

Semua pembahasan diatas, maka jelas terlihat semua parameter elastisitas yang di dapatkan berbanding lurus dengan kenaikan konsentrasi $\mathrm{NaCl}$. Semakin besar konsentrasi larutan yang menyaturasi sampel maka elastisitas sampel akan semakin besar (al Hagre \& Müller, 2000). Parameter elastisitas core kering lebih besar dari pada core tersaturasi, hal ini dikarenakan adanya gaya tarik menarik antara pasir ketika core diberi tekanan. Kecepatan gelombang yang diukur mendekati referensi kecepatan gelombang primer pada pasir tersaturasi air garam (air laut), yaitu sebesar 1,6-1,8 Km/s (Richardson, 1993), dimana kadar $\mathrm{NaCl}$ pada air laut berkisar sekitar 3\% (300000 ppm). Sedangkan pada hasil pengukuran kecpatan gelombang pada core tersaturasi $\mathrm{NaCl}$ dengan konsentrasi $300000 \mathrm{ppm}$ adalah sebesar $1764,706 \mathrm{~m} / \mathrm{s}$. Dari perbandingan diatas didapatkan persen kesalahan 9,29\%. Perbedaan dikarenakan pada airlaut tidak hanya terdapat $\mathrm{NaCl}$, tetapi juga terdapat unsur-unsur lain. Banyaknya unsur lain ini mengakibatkan banyaknya perbedaan densitas pada core yang mampu mempengaruhi perambatan gelombang elastik.

Selain itu kecepatan gelombang elastik juga ditentukan oleh densitas dan tekanan. Konsentrasi senyawa lain menyebabkan perbedaan densitas pasir tersaturasi air laut dan pasir tersaturasi larutan $\mathrm{NaCl}$. Perbedaan tekanan juga mempengaruhi kecepatan gelombang elastik, jika semakin besar tekanan maka kerapatan partikel dan porositas pasir juga akan semakin besar (Gal, 1998; al Hagre \& Müller, 2000). Sedangkan untuk parameter elastisitas nilainya berbanding lurus dengan kecepatan gelombang elastik. Ruang lingkup yang lebih luas aplikasinya dapat dilihat pada besarnya nilai salinitas air laut dan pengaruhnya terhadap elastisitas pasir yang ada dipantai. Sebagian besar dari garam yang terdapat dilaut di dominasi oleh $\mathrm{NaCl}$, maka semakin besar salinitas berarti konsentrasi $\mathrm{NaCl}$ juga semakin besar dan elastisitas pasir dipantai yang menyerap air laut tersebut juga semakin besar.

\section{KESIMPULAN}

Berdasarkan hasil penelitian dan analisis core pasir yang disaturasi larutan $\mathrm{NaCl}$ dengan konsentrasi yang divariasikan, kesimpulan yang dapat diambil adalah sebagai berikut.

1. Waktu tempuh gelombang seismik pada core berbanding terbalik dengan konsentrasi $\mathrm{NaCl}$ yang disaturasikan, sedangkan kecepatannya berbanding lurus. Semakin besar konsentrasi $\mathrm{NaCl}$, maka waktu tempuh gelombang semakin kecil dan kecepatan gelombang seismik akan semakin besar. 
2. Nilai parameter elastis core berbanding lurus dengan konsentrasi $\mathrm{NaCl}$ yang disaturasikan. Semakin besar konsentrasi $\mathrm{NaCl}$ semakin elastis core.

3. Hubungan antara parameter elastisitas dan konsentrasi $\mathrm{NaCl}$ membentuk hubungan kuadrat sesuai dengan hubungan antara kecepatan gelombang elastik dan parameter elastik core.

4. Parameter elastisitas core kering lebih besar daripada core tersaturasi, hal ini disebabkan oleh gaya tarik-menarik antara pasir lebih besar ketika core tidak disaturasi oleh larutan.

5. Perbedaan kecepatan gelombang elastik pada pasir tersaturasi larutan $\mathrm{NaCl}$ dan air laut disebabkan karena pada air laut terdapat beberapa senyawa lain selain $\mathrm{NaCl}$ dimana banaykya jenis senyawa ini menyebabkan perbedaan densitas yang dapat mempengaruhi perambatan gelombang elastik.

\section{UCAPAN TERIMA KASIH}

Penulis mengucapkan terima kasih tasa fasilitas yang diberikan Kelompok Fisika Bumi, urusan FIsika Universitas Riau atas fasilitas laboratorium yang diberikan. Paper ini juga didedikasikan kepada Alm Dr. Muhammad Edisir, MT selaku pembimbing selama penelitian berlangsung.

\section{DAFTAR RUJUKAN}

Ahied, M. (2010). Konversi Konstanta ELastik DInamik ke Statik pada Porositas Hidrokarbon Berpasir (Sandstone), Rekayasa, 3(2), 137-141.

al Hagre, S. A., \& Müller, C. (2000). GPR study of pore water content and salinity in sand, Geophysical Prospecting, 48, 63-85.

Biot, M. (1998). Theory of Propagation of Elastic Waves in a Fluid Saturated Porous Solid. I Low Frequency. Geophysics Reprint Series, 10, 393-397.

Davis, R., Selvadurai, A. (1996). Elasticity and Geomechanics. Cambridge University Press: Newyork.

Kang, M., \& Lee, J. S. (2015). Evaluation of the freezing - thawing effect in sand - silt mixtures using elastic waves and electrical resistivity. Cold Regions Science and Technology, 113, 1-11.

Li, M., Chai, S., Du, H., \& Wang, C. (2016). Effect of chlorine salt on the physical and mechanical properties of inshore saline soil treated with lime. Soils and Foundations, 56(3), 327-335.

Qadafi, M., Amin, B., Edisar, M. (2015). Analisis kelayakgunaan air tanah dalam ditinjau dari aspek kualitas dan geologi lingkungan di Kota Tembilahan, Indragiri Hilir. Jurnal Ilmu Lingkungan, 9(2), 131-142.

Richardson, M., Brigs, K. (1993). Empirical Predictions of Seafloor Properties Based on Remotely Measured Sediment Impedance. Marine Geosciences Division, Naval Research Laboratory, Stennis Space Center MS 39529-5004.

Sudjianto, A. (2003). "Stabilisasi Tanah Lempung Ekspansif dengan Garam Dapur ( $\mathrm{NaCl})$ ". Jurusan Teknik Sipil Universitas Widyagama: Malang.

Sun, Q., Li, D., \& Wang, S. (2015). Test on triaxial shear of artificial frozen saline sand. Coal Technol, 34(4), 105-107.

Wang, Z., Nur, A. (1998). Elastic Wave Velocities in Pourous Media. Geophysic Reprint Series, 10, 233-239.

Xu, X., Wang, Y., Bai, R., Zhang, H., \& Hu, K. (2016). Effects of sodium sulfate content on mechanical behavior of frozen silty sand considering concentration of saline solution. Results in Physics, 6, 1000-1007. 
Muammar Qadafi, Usman Malik

Zemansky. S. (1994). Fisika untuk Universitas 1. Binacipta: Jakarta. 